\author{
E. Bobbioni-Harsch $\cdot$ J. Sztajzel $\cdot$ V. Barthassat • \\ T. N. O. Lehmann · K. Sievert · G. Chassot $\cdot$ O. Huber • \\ P. Morel · A. Golay $\cdot$ F. Assimacopoulos-Jeannet
}

\title{
The effect of insulin on cardiac autonomic balance predicts weight reduction after gastric bypass
}

Received: 16 November 2004 / Accepted: 6 March 2005 / Published online: 4 June 2005

C) Springer-Verlag 2005

\begin{abstract}
Aims/hypothesis: The aim of this study was to assess the predictive role of autonomic reactivity in body weight loss induced by gastric bypass. Methods: A group of 22 morbidly obese subjects, who were due to undergo a gastric bypass, were submitted, before surgery, to a euglycaemic-hyperinsulinaemic clamp, during which a continuous recording of the ECG was performed. The effect of insulin on cardiac autonomic balance was evaluated by performing power spectral analysis of heart rate variability. The low-to-high frequency ratio was calculated before and during the clamp and its modifications were expressed as $\%$ delta low-to-high frequency ratio $(\% \Delta \mathrm{L}: \mathrm{H})$. Results: Preoperative $\% \Delta \mathrm{L}: \mathrm{H}$ showed a significant ( $p=0.0009, r^{2}=0.43$ ), positive relationship to the reduction of body weight, measured 1 year after surgery and expressed as $\%$ excess weight loss (\% EWL). Preoperative BMI was also significantly $\left(p=0.0009, r^{2}=0.43\right)$ negatively related to the 12 -month \% EWL. In a multiple regression analysis, $\% \Delta \mathrm{L}: \mathrm{H}$ remained a significant $(p=0.003)$, independent predictor of body weight loss, even when preoperative BMI or age, $\%$ fat mass, insulinaemia and glucose disposal were taken into account. Conclusions/ interpretation: The best correction of excess body weight
\end{abstract}

E. Bobbioni-Harsch $(\bowtie) \cdot$ V. Barthassat ·

T. N. O. Lehmann - A. Golay

Service of Therapeutic Education for Chronic Disease,

Geneva University Hospital,

1211 Geneva, Switzerland

e-mail: Elisabetta.Harsch@hcuge.ch

Tel.: +41-22-3729703

Fax: +41-22-3729715

J. Sztajzel $\cdot$ K. Sievert

Service of Cardiology, Geneva University Hospital,

Geneva, Switzerland

G. Chassot · O. Huber · P. Morel

Service of Digestive Surgery, Geneva University Hospital, Geneva, Switzerland

F. Assimacopoulos-Jeannet

Department of Cell Physiology and Metabolism,

Geneva Medical School,

1211 Geneva, Switzerland was achieved by those obese subjects who had a preserved capacity to shift their cardiac autonomic balance towards a sympathetic prevalence in response to an euglycaemichyperinsulinaemic clamp. Further studies are needed to elucidate the mechanisms through which the autonomic nervous system influences weight reduction.

Keywords Autonomic nervous system - Body weight loss $\cdot$ Obesity $\cdot$ Roux-en-Y gastric bypass

Abbreviations \% EWL: \% excess weight loss $\% \Delta \mathrm{L}: \mathrm{H}$ : $\%$ delta low-to-high frequency ratio . $\%$ FM: $\%$ fat mass . LBM: lean body mass - LF: low frequency $\cdot$ HF: high frequency $\cdot \mathrm{HRV}$ : heart rate variability

\section{Introduction}

Bariatric surgery is the most efficient approach in the treatment of morbid obesity [1]. In particular, Roux-en-Y gastric bypass [2] has been demonstrated to yield satisfactory results both in terms of extent and long-term maintenance of weight loss [3, 4]. By this technique, an average of excess weight loss ( $\%$ EWL) of over $60 \%$ has been repeatedly reported (review in [5]). Despite these excellent results, a large individual variability in outcome of bariatric surgery is commonly observed, and, in a minority of cases, patients do not obtain a 50\% EWL, considered as the inferior limit for a satisfactory result [6]. Thus, psychological, anthropometric, metabolic and neurological patient characteristics have been evaluated, in preoperative conditions, in order to prove any predictive parameter. For instance, it has been demonstrated that some psychological traits, such as anxiety and excessive health concerns, are linked to a less satisfactory result after gastric bypass [7], whereas patients showing eating disorders are likely to regain weight at long-term follow-up [8, 9]. Among the anthropometric characteristics, initial BMI $[10,11]$ plays an important role in surgically induced body weight loss. Diabetes [12] has also been suggested as a predictor of a lesser weight reduction following bariatric surgery. 
In a previous study [13], we investigated the sympathetically mediated vasoconstrictive response to a deep inspiration, at the capillary level, in a group of obese subjects undergoing a gastric bypass. We were able to demonstrate that an elevated sympathetic reactivity was associated significantly with a larger \% EWL, 12 months after the operation. This result is potentially useful in providing a predictive parameter of the gastric bypass outcome. More importantly, it also permitted a better understanding of the complex physiopathology of the weight loss process. For this reason, it seemed important to further characterise the predictive role of autonomic reactivity in obese patients undergoing a gastric bypass. Therefore, we investigated the cardiac autonomic balance by performing spectral analysis of the heart rate variability (HRV) before and during an euglycaemic-hyperinsulinaemic clamp in a group of obese subjects before the surgical intervention. Several studies have investigated extensively the stimulatory effect of insulin on sympathetic activity at the cardiac level [14-17]. Thus, it has been demonstrated that, in healthy subjects, increased insulin plasma levels induce a shift of the autonomic balance toward a sympathetic predominance [14, 15]. However, in insulin-resistant states, such as type 2 diabetes, hypertension or family history of diabetes, cardiac autonomic responsiveness is altered $[16,17]$. In obese subjects, characterised by a high degree of insulin resistance, the autonomic response to hyperinsulinaemia has been reported to be either blunted [15] or even completely abolished [14], suggesting a variable pattern of autonomic responsiveness, among an obese population. The aim of the present study was to investigate whether the variability of the outcome of bariatric surgery could be linked to the individual responsiveness of the autonomic nervous system.

\section{Subjects, materials and methods}

A group of 22 morbidly obese women (age $38 \pm 2$ years) undergoing a Roux-en-Y gastric bypass participated in the study. Among the patients, two were postmenopausal and two were diabetic under oral treatment. Five patients had impaired fasting glycaemia, i.e. between 6.0 and $6.9 \mathrm{mmol} /$ 1 [18]. Five subjects were under antihypertensive treatment; no one was receiving beta-blocker agents. Patients were informed about the methods and the design of the study, which had been previously approved by the local Ethical Committee, and gave their written consent. At the beginning of the study, patients were in conditions of stable body weight, i.e. their weight had not varied more than $5 \%$ during the previous 6 months.

As previously indicated, patients were submitted to a Roux-en-Y gastric bypass [19]. According to this surgical procedure, a small stomach pouch (50-ml volume) is first separated from the distal stomach; then, a Y-shaped section of the small intestine is connected to the gastric pouch to bypass the duodenum and a part of the jejunum. Finally, this bypassed portion of the intestine is attached more distally to the small bowel.
Before surgery, patients were admitted to the hospital in the morning, after a 10-h fasting period, and anthropometric measurements, i.e. body weight, height and body composition by bioelectrical impedance [20], waist and hip measurements were performed. Excess weight $(\mathrm{kg})$ was calculated as: actual weight-normal weight. Normal body weight of each patient, corresponding to a body mass index of $25 \mathrm{~kg} / \mathrm{m}^{2}$, was calculated as: $25 \times$ height $^{2}(\mathrm{~m})$.

After voiding, venous catheters and a Holter device were placed for ECG recording; then patients remained quiet in a supine position for a 30-min period, during which a first basal ECG record was performed. A 120-min euglycaemic, hyperinsulinaemic clamp test was then performed, as previously described [21]. Briefly, a priming dose of insulin was administered during the first $10 \mathrm{~min}$ of the test, in order to rapidly increase the circulating insulin levels. The total amount of insulin administered during this 10-min period was $0.8 \mathrm{U} \mathrm{m}^{-2}$ of body surface. An insulin infusion was then maintained at the constant rate of $0.04 \mathrm{U} \mathrm{m}^{-2} \mathrm{~min}^{-1}$ until the end of the test. A $20 \%$ glucose solution was infused at variables rates, in order to maintain glycaemia at a value of $5 \mathrm{mmol} / \mathrm{l}$. Blood samples were drawn every 5 min in order to measure glucose levels and to adjust the rate of glucose infusion. During the last $30 \mathrm{~min}$ of the test, i.e. when an insulin and glucose steady state was reached, glucose uptake was measured and expressed in $\mathrm{mg} / \mathrm{kg}$ of lean body mass (LBM) per min. Plasma glucose was measured enzymatically [22] using a glucose analyser (Beckman Instruments, CA, Fullerton, USA); plasma insulin was determined by radioimmunoassay, using commercial kits (Linco Research, Inc., St. Charles, MI, USA).

During the steady-state period of the clamp, a second ECG recording was performed.

HRV spectral measurements were performed on the two 30-min recording periods by a non-parametric method, the fast Fourier transformation. The following spectral bands were analysed: the low frequency (LF) and the high frequency (HF) power, as well as the LF: HF ratio. The LF component is modulated by both the sympathetic and parasympathetic nervous systems and thus reflects a mixture of both autonomic inputs. The HF component is generally defined as a marker of vagal modulation. The LF: HF ratio reflects the global sympathovagal balance and is used as a measure of this balance [23].

The modifications of the LF: HF ratio induced by euglycaemic hyperinsulinaemia (i.e. during the clamp) were calculated as $\% \Delta \mathrm{L}: \mathrm{H}$ from the basal value (i.e. before the clamp).

In order to reduce the effect of artefacts and of the changes in total power, low frequency and high frequency were also expressed in normalised units (NU). The normalisation of LF and HF was obtained by subtracting from total power the very low frequency component. This calculation is useful when evaluating the effects of different interventions in the same subject or when comparing subjects with major differences in total power [24].

Body weight was remeasured 3 and 12 months after surgery, and weight reduction was expressed as \% excess 
Table 1 Metabolic and autonomic parameters measured before and during the steady-state period of the clamp, in preoperative conditions

\begin{tabular}{lcc}
\hline & Basal & Clamp \\
\hline Glycaemia (mmol/l) & $5.6 \pm 0.3$ & $5.2 \pm 0.1$ \\
Insulinaemia $(\mathrm{ng} / \mathrm{ml})$ & $1.2 \pm 0.1$ & $5.1 \pm 0.4$ \\
Glucose uptake $(\mathrm{mg} / \mathrm{kg}$ of $\mathrm{LBM} / \mathrm{min})$ & - & $3.4 \pm 0.4$ \\
Low-to-high ratio & $2.1 \pm 0.5$ & $2.4 \pm 0.5$ \\
\hline
\end{tabular}

weight loss, i.e. (excess weight-weight reduction)/excess weight $\times 100$.

Weight loss was also expressed as \% of initial weight loss, i.e. weight reduction/initial body weight $\times 100$.

Simple and multiple regression analysis as well as ANOVA for repeated measurements were used for the statistical analysis. Results are indicated as means $\pm \mathrm{SEM}$ and two-tailed $p$ value for the significance.

\section{Results}

As indicated in Table 1, insulin plasma levels during the clamp were increased from $1.2 \pm 0.1$ to $5.1 \pm 0.4 \mathrm{ng} / \mathrm{ml}$, while glycaemia was maintained at a value of $5.2 \pm 0.1 \mathrm{mmol} / \mathrm{l}$. Glucose uptake was $3.4 \pm 0.4 \mathrm{mg} / \mathrm{kg}$ of $\mathrm{LBM} / \mathrm{min}$.

The mean value of the low-to-high frequency changed from $2.05 \pm 0.45$ in basal to $2.39 \pm 0.53$ during the test. This difference was not statistically significant $(p=0.26)$, when analysed by ANOVA for repeated measurements. As indicated by Fig. 1, the $\mathrm{L}$ : $\mathrm{H}$ ratio showed a large individual variability both before and during the clamp.

Among the parameters measured in preoperative conditions, $\% \Delta \mathrm{L}$ : $\mathrm{H}$ showed a significant negative relationship with age and $\% \mathrm{FM}(p=0.04$ and $p=0.03$, respectively). No significant relationship was found between $\% \Delta \mathrm{L}: \mathrm{H}$ and glucose disposal $(p=0.77)$.

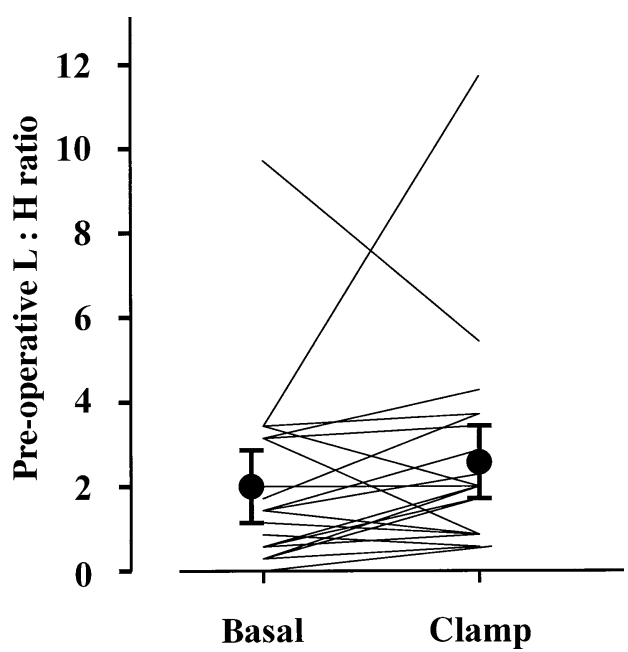

Fig. 1 Individual values of low-to-high frequency ratio measured before and during the clamp, in preoperative conditions
Table 2 Anthropometric parameters measured in the study group before and 3 and 12 months after gastric bypass

\begin{tabular}{lccc}
\hline & Before surgery & 3 months & 12 months \\
\hline Body weight $(\mathrm{kg})$ & $119.7 \pm 3.2$ & $100.0 \pm 3.1$ & $81.30 \pm 3.3$ \\
BMI $\left(\mathrm{kg} / \mathrm{m}^{2}\right)$ & $46.0 \pm 1.0$ & $38.1 \pm 1.1$ & $31.3 \pm 1.3$ \\
LBM $(\mathrm{kg})$ & $60.6 \pm 1.7$ & $54.3 \pm 1.7$ & $49.5 \pm 1.2$ \\
\% FM & $50.0 \pm 0.6$ & $46.4 \pm 0.7$ & $40.7 \pm 1.7$ \\
Waist-to-hip ratio & $0.89 \pm 0.01$ & $0.85 \pm 0.01$ & $0.82 \pm 0.01$ \\
\% Excess weight loss & - & $38.8 \pm 2.3$ & $73.0 \pm 4.8$ \\
\hline
\end{tabular}

ANOVA for repeated measurements: all 3 and 12 months values are significantly different from baseline for at least $p=0.0002$

After surgery, body weight sharply decreased between 0 and 3 months (rapid phase body weight loss), then it continued to decrease more slowly between 3 and 12 months (slow phase body weight loss) (Table 2). The \% excess weight loss was $38.8 \pm 2.3$ and $73.0 \pm 4.8 \%$, respectively, 3 and 12 months after surgery (Table 2): this means that more than half of the global correction of excess body weight was obtained during the rapid phase ( $0-3$ months) of body weight loss.

Weight reduction, expressed either as \% EWL (Fig. 2a) or as \% reduction of initial weight (Fig. 2b), showed a significant relationship with preoperative $\% \Delta \mathrm{L}: \mathrm{H}(p=$ $0.0009, r^{2}=0.43$ and $p=0.001, r^{2}=0.42$, respectively). Per-
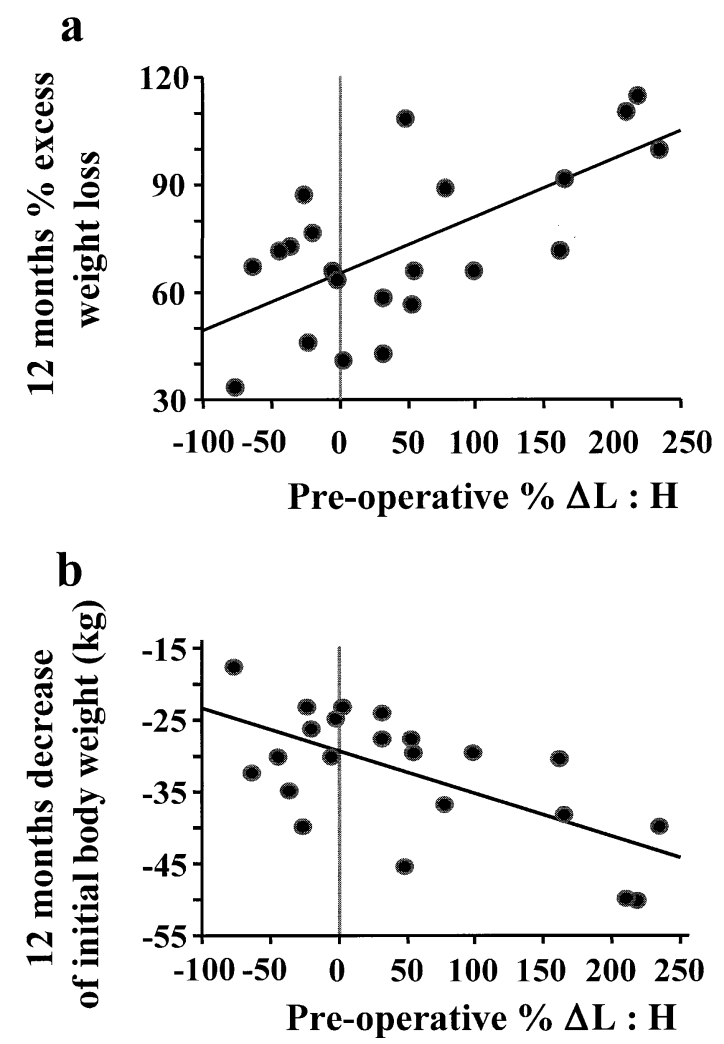

Fig. 2 Relationship between the insulin-induced modifications of the $\mathrm{L}: \mathrm{H}$ ratio $(\% \Delta \mathrm{L}: \mathrm{H})$, measured in preoperative conditions vs a the $\%$ excess weight loss $\left(p=0.0009, r^{2}=0.43\right.$, coef. $\left.=0.16\right)$ and vs b $\%$ decrease of initial body weight $\left(p=0.01, r^{2}=0.42\right.$, coef. $\left.=-0.06\right)$ 


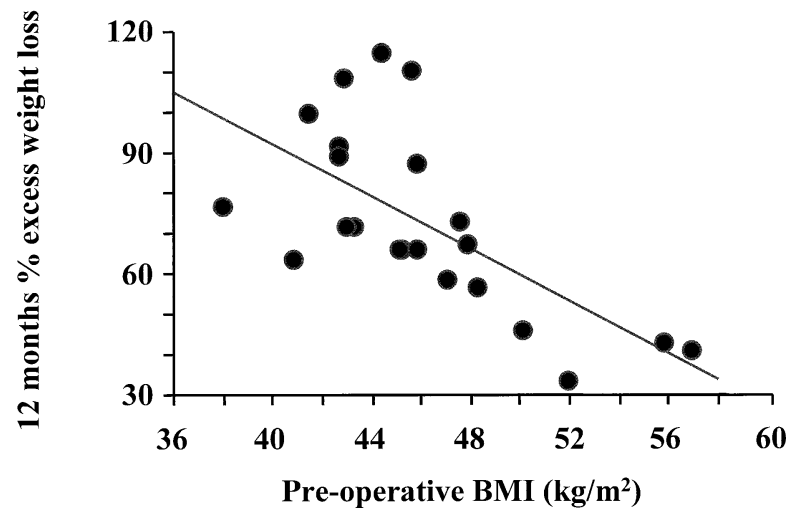

Fig. 3 Negative relationship between BMI $\left(\mathrm{kg} / \mathrm{m}^{2}\right)$, measured in preoperative conditions and the $\%$ excess weight loss, measured 12 months after surgery $\left(p=0.0009, r^{2}=0.44\right.$, coef. $\left.=-3.24\right)$

cent EWL also showed a significant $\left(p=0.0009, r^{2}=0.44\right)$, negative relationship with preoperative BMI (Fig. 3). When LF and HF were expressed in normalised units (NU), $\% \Delta \mathrm{L}: \mathrm{H}$ remained significantly related to $\% \mathrm{EWL}(p=$ $0.003, r^{2}=0.34$ ).

When analysed by multiple regression analysis (Table 3 ), $\% \Delta \mathrm{L}: \mathrm{H}$ remained a significant $(p=0.003)$ predictor of $\%$ EWL, even when preoperative BMI was taken into account. Together, the $\% \Delta \mathrm{L}: \mathrm{H}$ and preoperative BMI explained $61 \%$ of the variability in the correction of excess body weight, obtained 1 year after surgery.

The extents of weight reduction obtained during the rapid and the slow phase of body weight loss, respectively, were evaluated separately in multiple regression analysis (Table 3). This revealed that preoperative BMI significantly $(p=0.01)$, negatively influenced weight reduction during the rapid phase, whereas $\% \Delta \mathrm{L}: \mathrm{H}$ was significantly ( $p=0.003$ ), positively related to weight reduction occurring during the slow phase of postoperative body weight loss.

When, in a multiple regression analysis, preoperative age, \% FM, insulinaemia and glucose disposal were taken into account; $\% \Delta \mathrm{L}: \mathrm{H}$ remained a significant $(p=0.007)$, independent predictor of \% EWL (Table 4).

Table 3 Multiple regression analysis of extent of weight reduction, evaluated either as total \% excess weight loss 12 months after surgery, or as \% excess weight loss obtained respectively during the fast ( $0-3$ months) and the slow (3-12 months) phase of body weight loss

\begin{tabular}{|c|c|c|c|}
\hline \multirow{2}{*}{$\frac{\text { Dependent variable }}{\text { \% Excess weight loss }}$} & \multicolumn{2}{|c|}{ Independent variables } & \multirow[t]{2}{*}{$r^{2}$} \\
\hline & $\% \Delta \mathrm{L}: \mathrm{H}$ & BMI & \\
\hline Total \% excess weight & $p=0.003$ & $p=0.003$ & 0.61 \\
\hline loss (0-12 months) & Coef. $=0.12$ & Coef. $=-2.45$ & \\
\hline Fast phase $\%$ excess weight & $p=0.29$ & $p=0.01$ & 0.41 \\
\hline loss $(0-3$ months $)$ & Coef. $=0.02$ & Coef. $=-1.24$ & \\
\hline Slow phase $\%$ excess weight & $p=0.003$ & $p=0.053$ & 0.51 \\
\hline loss (3-12 months) & Coef. $=0.09$ & Coef. $=-1.19$ & \\
\hline
\end{tabular}

Table 4 Multiple regression analysis of \% EWL measured 12 months after surgery vs several autonomic, anthropometric and metabolic parameters measured in preoperative conditions

\begin{tabular}{lrl}
\hline Dependent variable: \% EWL & & \\
\hline Independent variables & Coefficient & $p$ \\
\hline \% $\Delta \mathrm{L}: \mathrm{H}$ & 0.13 & 0.007 \\
Age (years) & 0.50 & 0.25 \\
\% FM & -5.13 & 0.01 \\
Insulinaemia (ng/ml) & 3.87 & 0.55 \\
Glucose disposal (mg/kg of LBM/min) & -0.08 & 0.96 \\
\hline
\end{tabular}

Preoperative glucose disposal, fasting glycaemia, insulinaemia and weight/height did not show any predictive role on $\%$ EWL.

\section{Discussion}

The main result of this study is the striking, positive relationship between postoperative weight reduction and preoperative insulin-stimulated shift of the cardiac autonomic balance toward a sympathetic prevalence. In keeping with our previous results [13], the present study further underlines the involvement of the autonomic nervous system in the outcome of surgically induced weight loss.

It is important to note that, in simple regression analysis, the insulin-stimulated autonomic reactivity (i.e. $\% \Delta \mathrm{L}: \mathrm{H}$ ) shows a predictive capacity as strong as the initial BMI, which, up to now, was considered one of the best predictors of weight loss after surgery [25]. In fact, when separately analysed, $\% \Delta \mathrm{L}: \mathrm{H}$, as well as preoperative $\mathrm{BMI}$, explained over $40 \%$ of the weight reduction variability (Figs. 2, 3). Autonomic reactivity exerts this predictive function independently of the initial BMI. When taken together, these two parameters were able to predict $60 \%$ of the variability of the bariatric surgery outcome at 12 months. Moreover, this predictive role still applies even when preoperative age, \% FM, insulinaemia and glucose disposal are taken into account (Table 4).

The presence of a rapid and a slow phase of weight reduction following gastric bypass has been well documented [26]: this profile is due mainly to the pattern of energy intake, which is extremely low in the early postoperative period and, then, progressively increases up to 1 year after surgery $[13,26,27]$. Our results clearly indicate that, besides energy intake, other factors can influence weight loss at different phases of the process. Thus, BMI plays a major role during the early postoperative period, whereas its influence becomes much weaker later on. Dixon et al. [25] demonstrated that preoperative BMI is strongly related to BMI measured 1 year, but not 2 years, after surgery. This suggests that initial BMI does not influence weight maintenance or regain. Our results show that, within the first postoperative year, initial BMI influences weight loss only during the rapid phase, i.e. when energy intake is generally very low. Inversely, sympathetic reactivity influences weight reduction positively during the 
tardive, slow phase. It has been reported that a severe caloric restriction elicits a remarkable reduction of the sympathetic activity, probably aimed at reducing the energy deficit [28]. The drastic reduction of food intake occurring soon after surgery could therefore 'shut off' the sympathetic nervous system and, by consequence, deprive it of any influence on weight loss during the early postoperative period.

Although our previous [13] and current results clearly establish that autonomic nervous system responsiveness is predictive of weight loss, the underlying mechanisms remain unknown.

Weight loss depends upon the extent of energy deficit, i.e. the difference between energy intake and energy expenditure. The autonomic nervous system could therefore influence weight loss by acting either on energy expenditure and/or on energy intake.

During severe caloric restriction, the overall sympathetic activity is blunted [28]: this could negatively influence energy expenditure. In turn, as we previously reported [29], a decrease in energy expenditure could significantly hamper body weight loss.

Caloric restriction also enhances lipolysis by increasing beta-adrenergic receptors in the adipose tissue $[30,31]$ and, in normal body weight subjects, the norepinephrine spillover from the fat depots [32]. In obese subjects, a blunted sympathetic activation in the adipose tissue district could lead to defective lipolysis and, by consequence, to a smaller weight reduction. In our study, the cardiac autonomic responsiveness could reflect that of the adipose tissue. Of course, this hypothesis still has to be demonstrated to be true. Interestingly, a recent paper [33] shows a significant negative relationship between a sympathetic predominance at the heart level and circulating adiponectin levels. Adiponectin secretion is submitted to an inhibitory control by the adrenergic system [34]. This result, therefore, suggests that an increased sympathetic cardiac activity parallels a sympathetic predominance in the adipose tissue.

In our experiments, euglycaemic hyperinsulinaemia did not significantly affect the cardiac autonomic balance, when evaluated in the whole group. This result is in agreement with those previously reported in the literature, where reduced [15] or absent [14] autonomic response to insulin have been reported, in obese subjects. However, within the study group, some subjects showed a preserved capacity to shift towards a sympathetic predominance, in response to insulin (Fig. 1). These same subjects were the ones who achieved the best corrections of their overweight after surgery. Autonomic activation was not significantly related to insulin sensitivity. This result confirms those of Muscelli et al. [35], who did not find any correlation between the metabolic and the cardiologic parameters in a group of obese patients. In our study, the autonomic responsiveness was influenced by age and \% FM, suggesting that the control of autonomic function is influenced by numerous factors. This multiple control could explain the lack of relationship between the metabolic and the autonomic parameters. It could also account for the variability in the autonomic responsiveness, even though this was found only in obese females.

Nevertheless, this individual variability allowed us to point out that a preserved autonomic flexibility is associated with a larger correction of excess body weight.

It is generally agreed that the autonomic nervous system works by sectors and, therefore, its activation or inhibition in an organ/tissue does not necessarily occurs elsewhere. For this reason, any possible correlation between cardiac autonomic responsiveness and the one of other tissues/ organs needs to be demonstrated. However, cardiac autonomic balance correlates with the autonomic nervous activity in muscle [36] and with circulating adiponectin [33], a hormone from the adipose tissue. On another hand, its alteration in obese states needs no further demonstration $[14,15]$. All these results justify the utilisation of cardiac autonomic activity when investigating the physiopathology of energy balance.

In conclusion, our results demonstrate a strong predictive role of autonomic nervous system reactivity on the extent of weight reduction. The elucidation of the mechanisms underlying this effect could provide us with important elements and improve our knowledge of the physiopathology of obesity and body weight loss.

Acknowledgements We are grateful to our volunteers whose availability made this work possible, as well as to Mrs N. Flores and Mrs F. Califano for their skilful secretarial and technical assistance. This study was supported by the Swiss National Fund for Scientific Research (grants no. 32-61339.00 and no. 3200-063624 FAJ) and by the Ernst et Lucie Schmidheiny Foundation.

\section{References}

1. Clegg A, Colquitt J, Sidhu M, Royle P, Walker A (2003) Clinical and cost effectiveness of surgery for morbid obesity: a systematic review and economic evaluation. Int $\mathrm{J}$ Obes 27: $1167-1177$

2. Griffen WO Jr, Young VL, Stevenson CC (1977) A prospective comparison of gastric and jejunoileal bypass procedures for morbid obesity. Ann Surg 186:500-509

3. Howard L, Malone M, Michalek A, Carter J, Alger S, Van Woert J (1995) Gastric bypass and vertical banded gastroplasty -a prospective randomized comparison and 5-year follow-up. Obes Surg 5:55-60

4. Jones KB Jr (2000) Experience with the Roux-en-Y gastric bypass, and commentary on current trends. Obes Surg 10:183185

5. Ballantyne GH (2003) Measuring outcomes following bariatric surgery: weight loss parameters, improvement in co-morbid conditions, change in quality of life and patient satisfaction. Obes Surg 13:954-964

6. Reinhold RB (1982) Critical analysis of long-term weight loss following gastric bypass. Surg Gynecol Obstet 155:385-394

7. Tsushima WT, Bridenstine MP, Balfour JF (2004) MMPI-2 scores in the outcome prediction of gastric bypass surgery. Obes Surg 14:528-532

8. Kalarchian MA, Marcus MD, Wilson GT, Labouvie EW, Brolin RE, LaMarca LB (2002) Binge eating among gastric bypass patients at long-term follow-up. Obes Surg 12:270-275

9. Hsu LKG, Sullivan SP, Benotti PN (1997) Eating disturbances and outcome of gastric bypass surgery: a pilot study. Int J Eat Disord 21:385-390 
10. Jiang D, Renquist KE, Mason EE, FACS, NBSR contributors (1991) Weight loss curve analysis. Obes Surg 1:373-380

11. Bobbioni-Harsch E, Huber O, Morel P, Chassot G, Lehmann T, Volery $\mathrm{M}$ et al (2002) Factors influencing energy intake and body weight loss after gastric bypass. Eur J Clin Nutr 56:551556

12. Perugini RA, Mason R, Czerniach DR, Novitsky YW, Baker S, Litwin DEM et al (2003) Predictors of complication and suboptimal weight loss after laparoscopic Roux-en-Y gastric bypass. Arch Surg 138:541-546

13. Bobbioni-Harsch E, Bongard O, Habicht F, Weimer D, Bounameaux H, Huber O et al (2004) Relationship between sympathetic reactivity and body weight loss in morbidly obese subjects. Int J Obes 28:906-911

14. Muscelli E, Emdin M, Natali A, Pratali L, Camastra S, Gastaldelli A et al (1998) Autonomic and hemodynamic responses to insulin in lean and obese humans. J Clin Endocrinol Metab 83:2084-2090

15. Paolisso G, Manzella D, Tagliamonte RM, Rizzo MR, Gambardella A, Varricchio M (1999) Effects of different insulin infusion rates on heart rate variability in lean and obese subjects. Metabolism 48:755-762

16. Bergholm R, Westerbarcka J, Vehkavaara S, Seppälä-Lindroos A, Goto T, Yki-Järvinen H (2001) Insulin sensitivity regulates autonomic control of heart rate variation independent of body weight in normal subjects. J Clin Endocrinol Metab 86:14031409

17. Lindmark S, Wiklund U, Bjerle P, Eriksson JW (2003) Does the autonomic nervous system play a role in the development of insulin resistance? A study on heart rate variability in firstdegree relatives of type 2 diabetes patients and control subjects. Diabet Med 20:399-405

18. Report of a WHO Consultation (1999) Definition, diagnosis and classification of diabetes mellitus and its complications. Part 1: diagnosis and classification of diabetes mellitus. World Health Organization, Geneva

19. Sugerman HJ, Kellum JM, Engle KM et al (1992) Gastric bypass for treating severe obesity. Am J Clin Nutr 55(Suppl 2):560S-566S

20. Segal KR, Van Loan M, Fitzgerald PI, Hodgdon JA, Van Itallie TB (1988) Lean body mass estimation by bioelectrical impedance analysis: a four-site cross-validation study. Am J Clin Nutr 47:7-14

21. DeFronzo RA, Tobin JD, Andres R (1979) Glucose clamp technique: a method for quantifying insulin secretion and resistance. Am J Physiol 237:E214-E223

22. Caraway WT (1987) Carbohydrate. In: Tietz NW (ed) Fundamentals of clinical chemistry, 2nd edn. WB Saunders Co, Philadelphia, p 427

23. Task Force of the European Society of Cardiology and the North American Society of Pacing and Electrophysiology (1996) Heart rate variability. Standards of measurement, physiological interpretation, and clinical use. Circulation 93:10431065
24. Montano N, Ruscone TG, Porta A, Lombardi F, Pagani M, Malliani A (1994) Power spectrum analysis of heart rate variability to assess the changes in sympathovagal balance during graded orthostatic tilt. Circulation 80:1826-1831

25. Dixon JB, Dixon ME, O'Brien PE (2001) Pre-operative predictors of weight loss at 1-year after lap-band surgery. Obes Surg 11:200-207

26. Trostler N, Mann A, Zilberbush N, Avinoach E, Charuzi I (1995) Weight loss and food intake 18 months following vertical banded gastroplasty or gastric bypass for severe obesity. Obes Surg 5:39-51

27. Brolin RE, Robertson LB, Kenler HA, Cody RP (1994) Weight loss and dietary intake after vertical banded gastroplasty and Roux-en-Y gastric bypass. Ann Surg 220:782-790

28. Saris WHM (1995) Effects of energy restriction and exercise on the sympathetic nervous system. Int J Obes 19:S17-S23

29. Bobbioni-Harsch E, Morel P, Huber O, AssimacopoulosJeannet F, Chassot G, Lehmann T et al (2000) Energy economy hampers body weight loss after gastric bypass. J Clin Endocrinol Metab 85:4695-4700

30. Barbe P, Stich V, Galitzky J, Kunesova M, Heiner V, Lafontan $M$ et al (1997) In vivo increase in beta-adrenergic lipolytic response in subcutaneous adipose tissue of obese subjects submitted to a hypocaloric diet. J Clin Endocrinol Metab 82:63-69

31. Hellström L, Reynisdottir S, Langin D, Rössner S, Arner P (1996) Regulation of lipolysis in fat cells of obese women during long-term hypocaloric diet. Int J Obes 20:745-752

32. Patel JN, Coppack SW, Goldstein DS, Miles JM, Eisen Hofer G (2002) Norepinephrine spillover from human adipose tissue before and after a 72-hour fast. J Clin Endocrinol Metab 87:3373-3377

33. Wakabayashi S, Aso Y (2004) Adiponectin concentrations in sera from patients with type 2 diabetes are negatively associated with sympathovagal balance as evaluated by power spectral analysis of heart rate variation. Diabetes Care 27:2392-2397

34. Fasshauer M, Klein J, Neumann S, Eszlinger M, Paschke R (2001) Adiponectin gene expression is inhibited by $\beta$-adrenergic stimulation via protein kinase A in 3T3-L1 adipocytes. FEBS Lett 507:142-146

35. Muscelli E, Camastra S, Catalano C et al (1997) Metabolic and cardiovascular assessment in moderate obesity: effect of weight loss. J Clin Endocrinol Metab 82:2937-2943

36. Pagani M, Montano N, Porta A, Malliani A, Abboud F, Birkett C et al (1997) Relationship between spectral components of cardiovascular variabilities and direct measures of muscle sympathetic nerve activity in humans. Circulation 95:1441-1448 